\title{
CONSTRUCTION PHASES ANALYSIS OF UNREINFORCED MASONRY BUILDINGS THROUGH EQUIVALENT FRAME MODEL
}

\author{
Francesco Pugi ${ }^{1}$, Alessio Francioso ${ }^{2 *}$ and Giacomo Sevieri ${ }^{3}$ \\ ${ }^{1}$ Aedes Software \\ 56028 San Miniato Basso, Pisa, Italy \\ info@aedes.it \\ ${ }^{2}$ National Technical University of Athens \\ 15780 Zografou, Athens, Greece \\ alessiofrancioso@gmail.com \\ ${ }^{3}$ University of Pisa, DESTEC \\ 56100 Pisa, Italy \\ giacomo.sevieri@unifi.it
}

Keywords: masonry structures, equivalent frame model, construction phases analysis, construction stages.

\begin{abstract}
Structural analysis of masonry buildings is affected by many uncertainties and characterized by issues related to the very nature of the material. In this scenario, refined analysis methodologies are confined to the research environment, while professional applications need simpler methodologies, which allow for a better understanding of the analysis results: the equivalent frame model is one of these methodologies. However, the method is affected by some issues, which, if not adequately addressed, may lead to unrealistic stress distributions. In this work, we propose a procedure that increases the reliability of the analysis results. It consists in the modification of the model depending on the nature of the acting loads in relation to the different construction phases of the structure. In addition, an extension of the method for the analysis of buildings constructed in different periods is introduced. Finally, the results of the analysis performed for a case study are presented in order to validate the proposed methods.
\end{abstract}




\section{INTRODUCTION}

Among the various methods available for structural analysis of masonry buildings, the "equivalent frame model" is the most widely used in the professional field, thanks to the simplicity of one-dimensional finite elements and the good capacity to assess the real behavior of the structure.

More accurate finite element models, which make use of shell or solid elements, are mainly employed in the research field. They require a rather high computational effort for being used in engineering practice and are still affected by uncertainties related to various parameters (in particular, the constitutive laws of the materials).

Furthermore, dealing with existing buildings it should be pointed out that the fundamental method of analysis is the kinematic analysis of the collapse mechanisms, which assesses the stability of the structure.

Static and dynamic, linear and nonlinear analyses performed on elastic models are meaningful only if the local collapse mechanisms have been prevented. They assess the resistance of the building, which is generally secondary to its stability. Therefore, elastic modelling should be kept simple avoiding excessive complexity. This is the reason why many national and international Standards [1] including Eurocodes [2] indicate the equivalent frame model as the reference methodology.

On the other hand, modelling of a spatial structure through one-dimensional finite elements implies some critical issues, most of them related to the fact that one single model is used for the analysis under different load actions with the same mechanical parameters, internal and external constraints. Adjacent walls significantly different in dimensions correspond to a local inhomogeneity in the stiffness distribution. In fact, the stresses migrate towards the most stiff elements, with consequent unrealistic stress distribution even if the sole self-weight of the walls is applied. Moreover, under the action of vertical loads, significant shear and bending moment acting on masonry piers and spandrels appear quite unrealistic, as well as tensile stress, which may occur in masonry piers usually due to big stiffness discrepancy at the various stories or differential displacements in the foundations.

These issues are not caused by the equivalent frame method, but by the way it is normally applied. In compliance with this modelling technique, a methodology that allows a more realistic stress distribution can be applied.

The methodology illustrated in the following paragraphs stems from the will to overcome the difficulties described above through a generalized algorithm valid for any masonry structure and automatically executable by software. This procedure is based on the diversification of the characteristics of the model (mechanical parameters of the materials, internal and external constraints) depending on the type of load action. Although the methodology is calibrated on the equivalent frame model, it introduces concepts related to the construction phases, which are valid regardless of the modelling technique applied.

\section{CONSTRUCTION PHASES ANALYSIS}

Analysis of the construction phases has long been used in structural engineering for specific structural typologies, such as bridges. In general, before a construction is completed, the static scheme of the structure evolves. The mechanical characteristics and the restraint conditions can be considered variable during the different construction phases, which are characterized by loads of different nature.

Normally, dealing with buildings, all the loads, whether they are vertical or horizontal, permanent or variable (including wind, seismic action) are applied to the same structural model, 
and the results of the analyses performed for the different load actions are then combined together. In frame structures, sufficiently regular in terms of geometry and stiffness, such as steel or reinforced concrete frame structures, this methodology leads to acceptable approximations. In masonry structures, instead, issues related to the stress distribution among the resistant elements may arise.

The proposed approach differentiates the structural scheme depending on the different load actions, which occur at different times during the life of the structure. While the structure is being built, it cannot be assumed that it behaves as a frame under the action of the self-weight; the frame will appear only once the construction is complete. The structure shows a frame behavior only under the actions that occur at the end of the construction: variable loads, wind and earthquake. Therefore, three construction phases have been defined and referred to as Phase 0 , Phase 1 and Phase 2.

In Phase 0, the permanent loads, both structural (G1) and non-structural (G2), are applied on a static scheme, which leads to a stress distribution consistent with the influence area of each element. In Phase 1, the vertical variable loads (Q) are applied on a static scheme, which allows occurrence of in-plane and out-of-the plane stresses in masonry piers, while spandrels remain unstressed. Finally, in Phase 2 horizontal variable loads, wind and seismic action, are applied to the structure: in this last phase, the equivalent frame is considered totally reacting.

\subsection{Phase 0}

While the structure is being built, it settles under its own weight; this leads each pier to be mainly subjected to axial force with a value close to the one calculated with the classic method of the influence areas. Bending or shear stress may occur in the elements in case of walls which are offset at the different stories or in case of vaults and arches, whose thrust stresses the adjacent piers in-plane and out-of-plane.

In Phase 0, only permanent loads, both structural and non-structural, are applied. In order to achieve the previously described behaviour, the piers are assumed fixed at the base and with an in-plane hinge at the top, while the spandrels are considered hinged in their plane, taking into account the arch-behaviour, that is, the presence of an ideal arch which transform the distributed load acting on the spandrel as point loads at its two ends. Therefore, the spandrels are unstressed under vertical actions, since they develop an "arch behaviour" instead of a "beam behaviour".

However, these hypotheses alone are not enough to ensure the desired behaviour. In fact, there remains the issue of stress migration due to large stiffness variation between adjacent elements. In addition, unrealistic moments may occur within irregular frames where piers are not continuous form foundations to top and lability may arise in the wall plane due to the applied releases.

The following modifications have been introduced in order to overcome these issues:

- Migration of stress due to sharp stiffness variation. Besides the pier restraints mentioned above (fixed end at the base and in-plane hinge at the top), the values of modulus of elasticity $\mathrm{E}$ and shear modulus $\mathrm{G}$ are amplified in order to obtain very stiff elements. In this way, the effects of stress redistribution due to different pier sections vanish, since the stresses are distributed within a rigid system. Furthermore, vertical translation is released in the rigid links between orthogonal walls, in this way a more realistic distribution of the slab loads is achieved, avoiding stress migration among transversal walls.

- Occurrence of local lability due to the applied releases. The figure below highlights the mechanism that may occur in the wall plane: the hinges introduced at the top of the piers and 
at the two ends of the spandrels are aligned, thus the system is labile. To overcome this issue the joint $\mathrm{X}$ and $\mathrm{Y}$ rotations are restrained at the top of the piers and, as a result, the system assumes a "shear-type" behaviour.

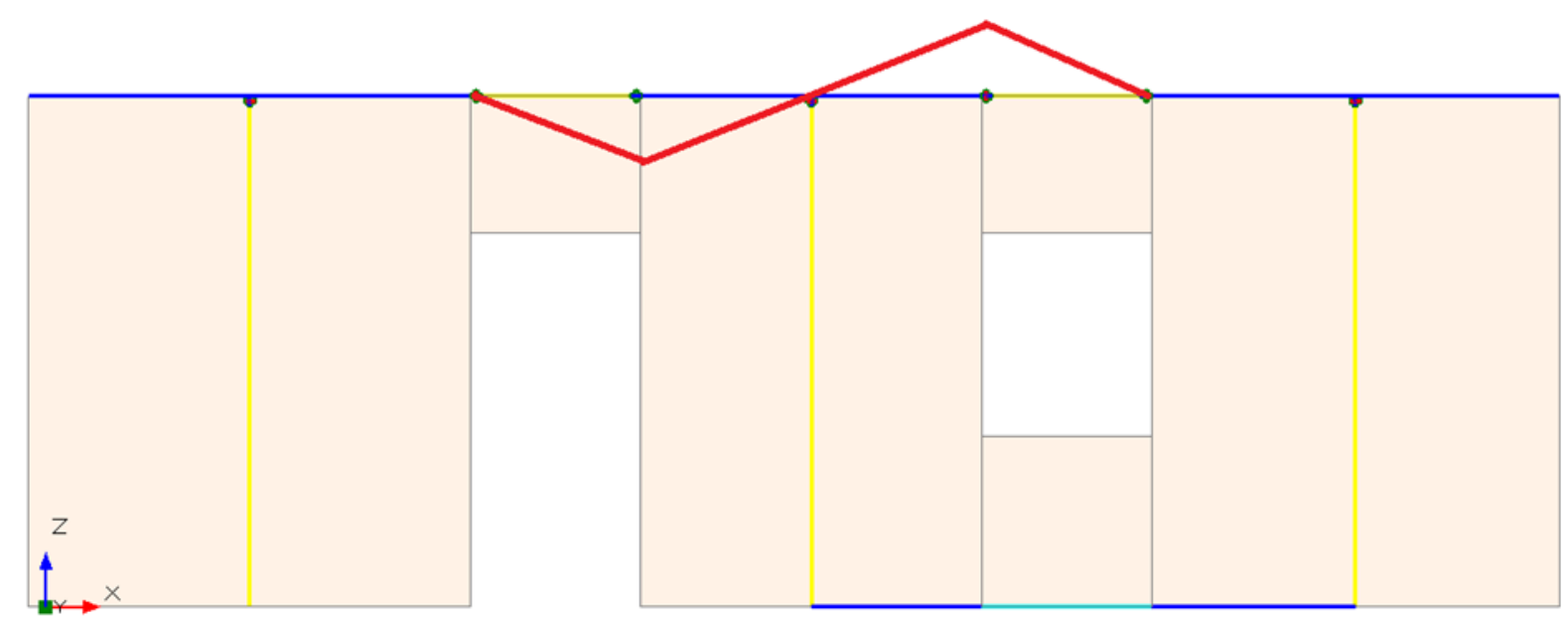

Figure 1. Possible lability in the wall plane.

In order not to create rigid relations among the joints, which may affect the distribution of the vertical loads, the hypothesis of rigid level and rigid slabs are ignored.

As regards the foundations, it should be pointed out that in masonry structures they are usually very stiff, they do not deflect and during the construction they settle under the weight of the structure. Therefore, in this phase it can be assumed that the stress are transferred to the ground through a rigid body and that differential settings capable to create stress states in the superstructure will occur in a later phase when the structure behaves as a spatial frame. In order to achieve the goal, first, the foundation joints at the base of the walls are fixed allowing evaluating the resultant of the action in terms of vertical load and bending moment. Then, the stress in the ground is determined using the formula for compression and flexure applied to the section defined by the foundation plan:

$$
\sigma(\xi, \eta)=N / A+N \cdot \eta_{N} \cdot \eta / J_{\xi}+N \cdot \xi_{N} \cdot \xi / J_{\eta}
$$

where: $\xi$ and $\eta$ are the coordinates of the vertex of each foundation frame in the global reference, $\mathrm{N}$ is the resultant vertical force, $\xi_{N}$ and $\eta_{N}$ are the eccentricity of $\mathrm{N}$ with respect to centroid of the section, A is the total area of the foundation plan, $J_{\xi}$ and $J_{\eta}$ are the second moment of inertia about the axes $\xi$ and $\eta$.

To sum up, the hypothesis introduced in Phase 0 are the following:

- Piers fixed at the base and with in-plane hinge at the top.

- Spandrels hinged in their plane at the two ends with arch-behavior.

- Amplified modulus of elasticity for masonry elements.

- Shear-type behavior for joints at the top of masonry piers.

- Vertical translation released for rigid links between orthogonal walls.

- Rigid levels (master-slave relations) and slab stiffness are ignored. 
- Rigid foundations and determination of soil stresses through the formula of compression and flexure applied to the section defined by the foundation plan.

\subsection{Phase 1}

In Phase 1, the vertical variable loads are applied to the equivalent frame. These loads occur once the structure is completely built, so it cannot be assumed that the structure settles under their action. Therefore, moments and shear force in masonry piers are considered plausible. However, since the vertical load acting in this phase are still static, the spandrels are modelled so as not to be subjected to bending moment and shear.

As regards the foundations, in this phase they can be modelled as beams on elastic soil according to Winkler theory, allowing for the occurrence of differential settlements.

To sum up, the described behavior is achieved through the following modification of the standard frame: spandrels are hinged in their plane with arch-behavior; rigid levels and slab stiffness are ignored.

\subsection{Phase 2}

In Phase 2, the horizontal loads (wind and seismic action) are applied to the completely reacting frame. Bending moments and shear forces are accepted in all the elements including spandrels. This is the last phase where the equivalent frames method is applied with the original formulation without modification of the elements.

\subsection{Combination of the results}

Construction phases analysis is performed by means of three different structural models, one for each phase. The final stress and strain state of each element is given from the combination of the results obtained for each phase, of course taking into account the combination coefficients.

However, modal analysis is carried out on the standard equivalent frame model (Phase 2), since it is representative of the dynamic behavior of the structure. In seismic analysis, the static effects obtained from Phase 0 and Phase 1 are combined with the seismic effects obtained from Phase 2.

\section{ANALYSIS OF THE CONSTRUCTION STAGES}

The study of the construction phases analysis provided the basis for developing a more accurate analysis procedure when dealing with buildings which have undergone modification in later construction stages. In particular, the study considers buildings that have been enlarged with the integration of new volumes, rather than those which have undergone a demolition. This case occurs frequently in the engineering practice, since interventions aimed to extend or raise an existing building are very common.

Looking at the very nature of the intervention, it is evident that it represent an extension of the construction phases methodology outlined in the previous paragraphs. Even in this case, the building can be analyzed considering three different construction phases, but it should be taken into account that when the enlargement has been built the original part of the structure was already consolidated.

For the purposes of the analysis the original structure is referred to as Structure A while the enlargement is referred to as Structure B. The construction phases analysis is performed through the analysis of the following models: 
- Model 0-A. This model consists only of the original structure modelled according to the hypothesis of Phase 0 . The analysis is performed for the corresponding permanent loads.

- Model $0-B$. The enlargement is modelled according to Phase 0 while the original structure is modelled according to Phase 1 . The analysis is performed for the permanent loads related to the enlargement.

- Model 1. Both original structure and enlargement are modelled according to Phase 1 . The analysis is performed for vertical variable loads.

- Model 2. Both original structure and enlargement are modelled according to hypothesis of Phase 2. The analysis is performed for horizontal variable loads (wind, seismic action).

Once all the analysis have been performed on the four models, the results are combined taking into account the combination coefficients provided by the Standards for each different load action.

\section{CASE STUDY}

The proposed methodology has been applied to the case of a three-story building located in Fivizzano, Tuscany [5]. The construction dates back to 1918. In 1967, the building has undergone renovations that led to the enlargement of ground floor and first floor. The layout of the structure, although rather simple, shows all the critical aspects related to the equivalent frame modelling and allows focusing the attention on the effects of the construction phases analysis.

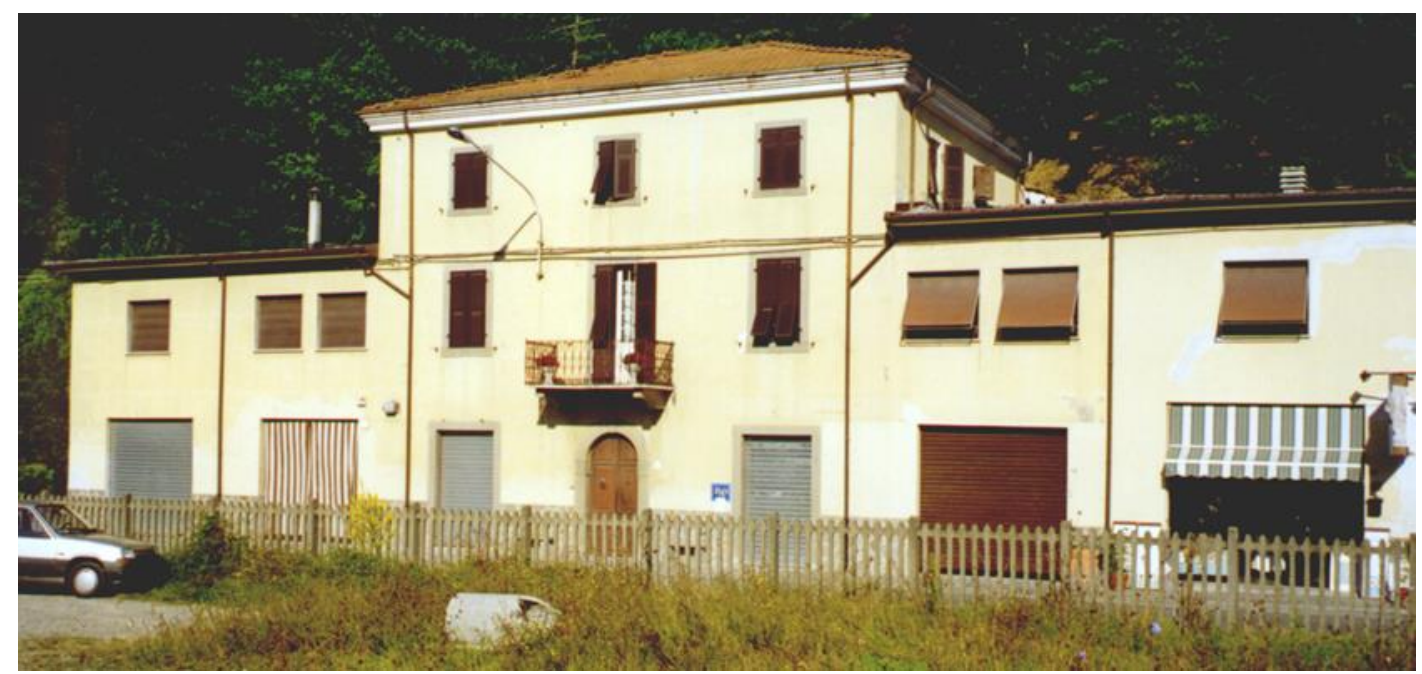

Figure 2. View of the building

The different typologies of masonry and slabs confirm that the structure was built in two different periods. The walls of the structure dating back to 1918 are made of irregular stone masonry, while the walls built in the later stage are made of brick masonry with regular pattern. The following figures show an elevation and two floor plan of the building, the different colors highlight the different construction stages. 


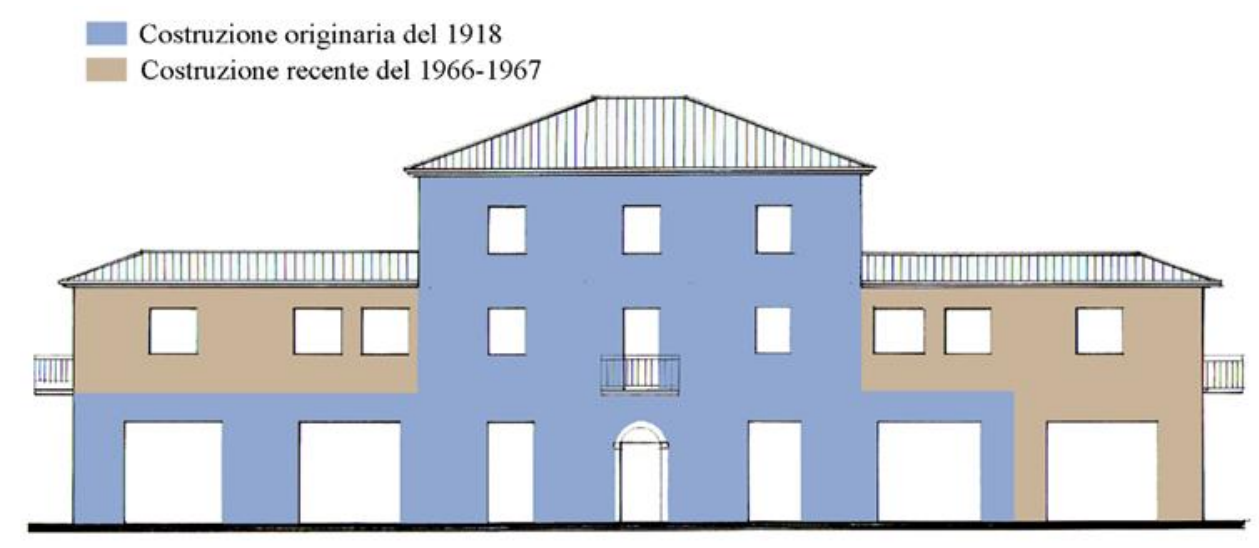

Figure 3. South-East Elevation

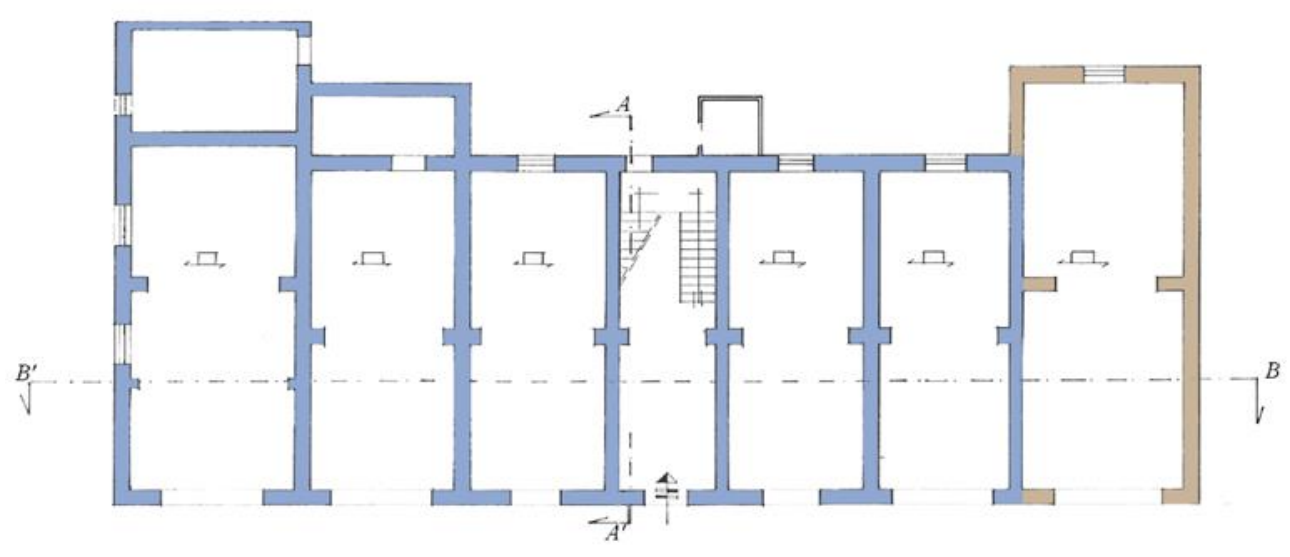

Figure 4. Plan of the Ground Floor.

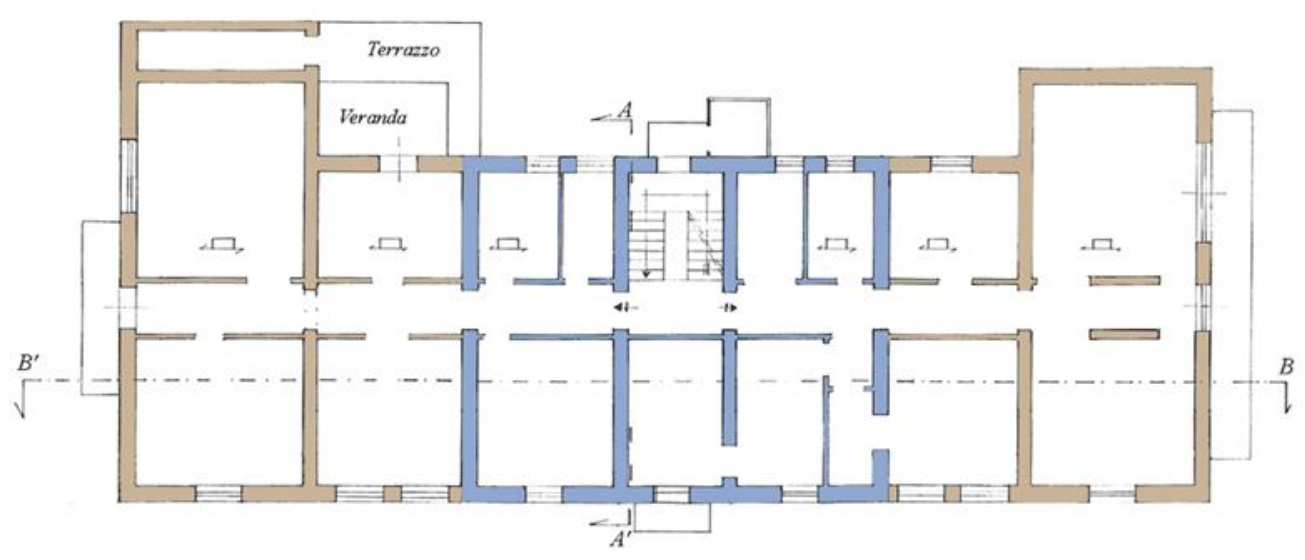

Figure 5. Plan of the First Floor

The analysis of the building was carried out according to three different approaches: (i) standard approach; (ii) construction phases analysis; (iii) analysis of the construction stages. The differences between the three methodologies are highlighted in terms of stress state resulting from linear static analysis.

\subsection{Standard approach}

The following figures show the modelling of the building through the standard equivalent frame method. 

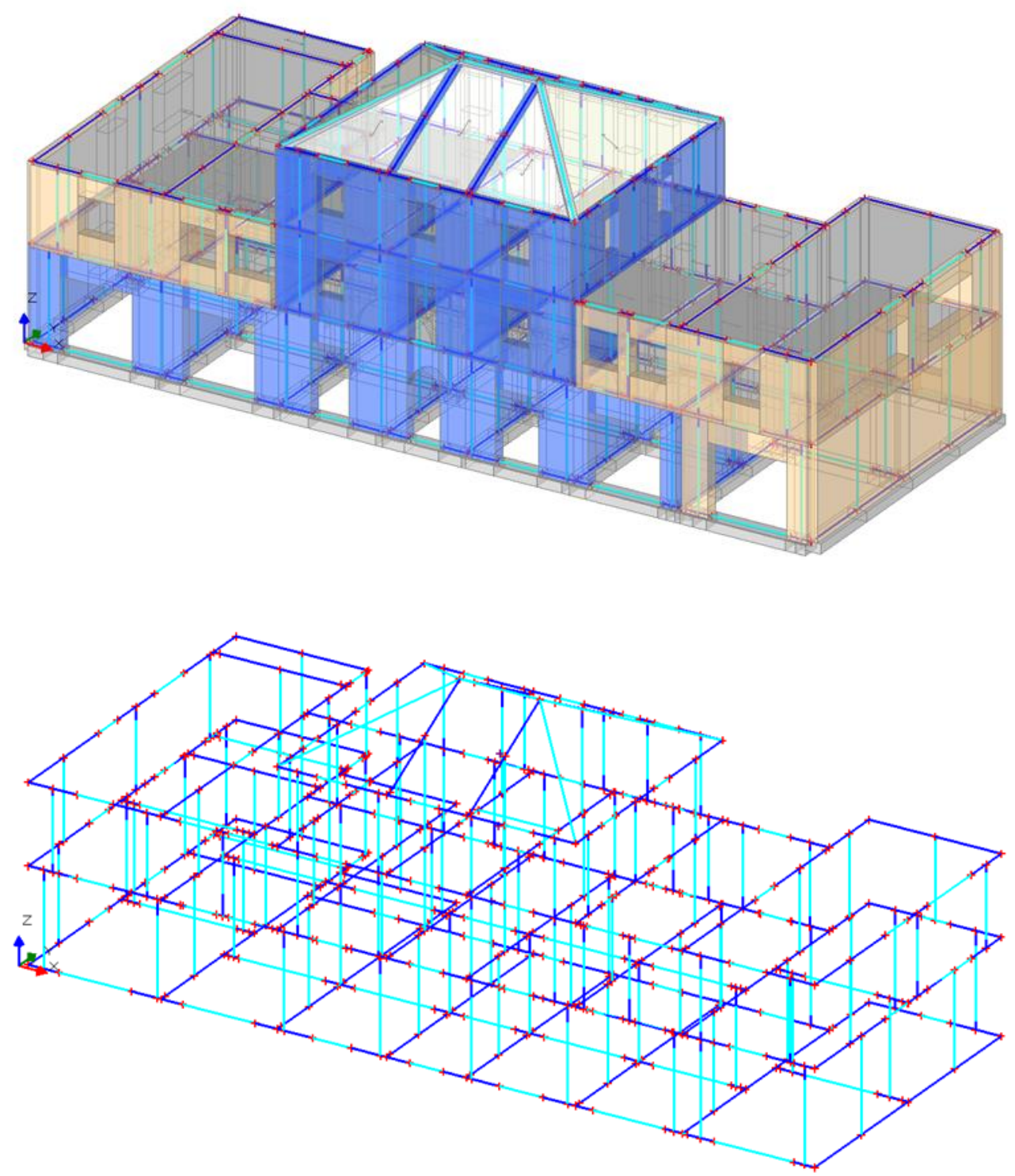

Figure 6. Standard equivalent frame model.

Masonry piers and spandrels are modelled through frame elements. Rigid links connect the spandrels to the adjacent piers and provide the connection between transversal walls. As a result each slab boundary is a closed polyline made of frame elements (spandrels and rigid links). The slabs in the original part of the building are considered deformable, while the ones made of concrete in the enlargement part are considered infinitely rigid. The spandrels are modelled assuming the arch-behavior [6 - 8]. As regards the foundations, they are modelled as beams on elastic soil with Winkler modulus $K=0.05 \mathrm{~N} / \mathrm{mm}^{3}$. The following table gives the mechanical properties of the masonry materials.

\begin{tabular}{lcccc}
\hline & \multicolumn{3}{c}{ Stone masonry } & Brick masonry \\
\hline Modulus of elasticity & E & 1600 & 5000 & $\mathrm{~N} / \mathrm{mm}^{2}$ \\
Shear modulus & G & 240 & 500 & $\mathrm{~N} / \mathrm{mm}^{2}$ \\
Weight per unit volume & W & 23.50 & 18.00 & $\mathrm{kN} / \mathrm{m}^{3}$ \\
\hline
\end{tabular}

Table 1. Mechanical properties of masonry materials 
Static linear analysis was performed with the aid of the software Aedes.PCM [9]. The results shown below refer to a load combination that includes only vertical loads with all the combination coefficients equal to 1 . Such combination, although not required by the Standards, is useful to simplify the comparison of the results. In fact, the scope of this first analysis is to highlight the critical aspects of the equivalent frame model. The following figure shows the axial force diagram.

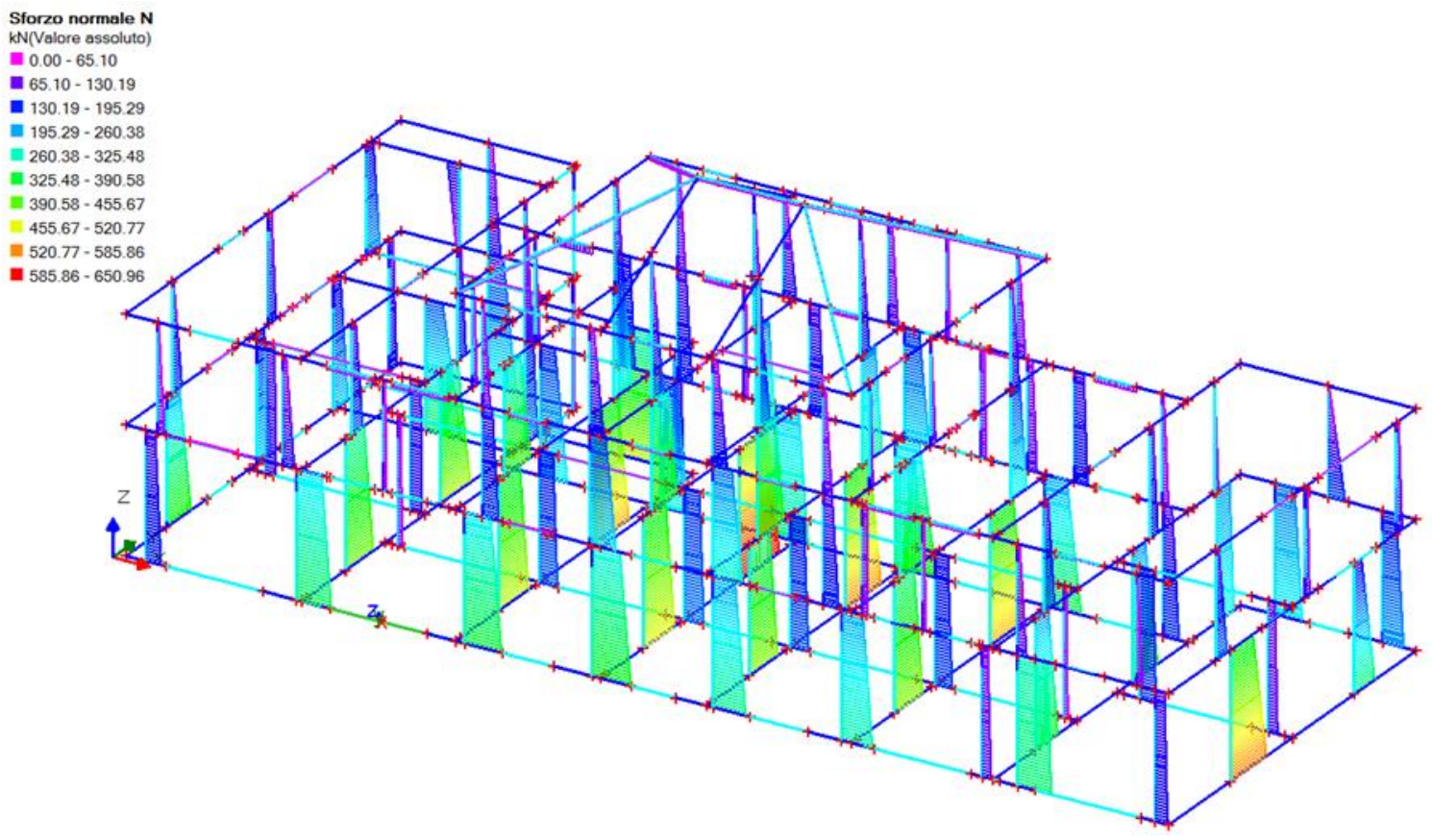

Figure 7. Static analysis. Axial force diagrams

Several issues affect the resulting stress distribution: masonry piers in tension, stress migration among adjacent elements, spandrels subjected to high bending moments and shear force. Let us focus our attention on the frontal alignment (Figure 8), evaluating the differences between the analysis results and a manual calculation of the stress state.

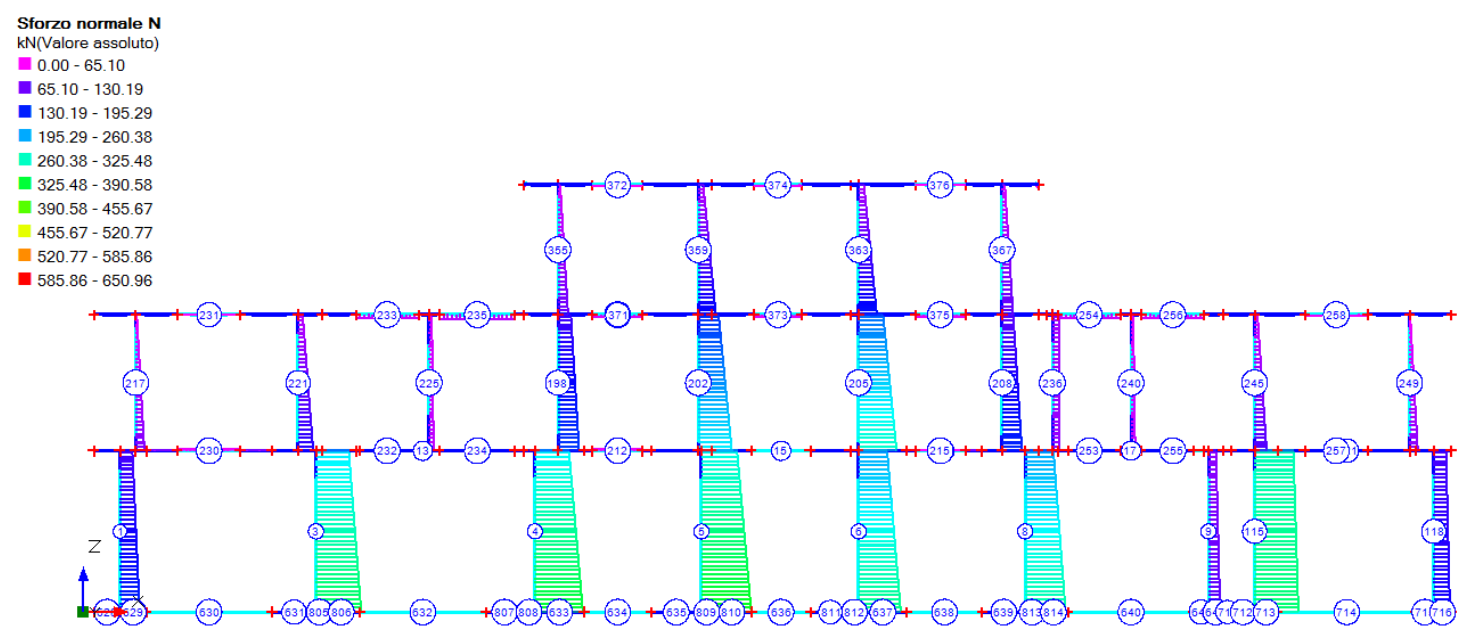

Figure 8. Axial force diagrams. Frontal alignment 
Piers 6 and 205 are perfectly aligned and definitely affected by an issue: looking at the axial force diagram we notice an unnatural decrease at the interface between the two elements.
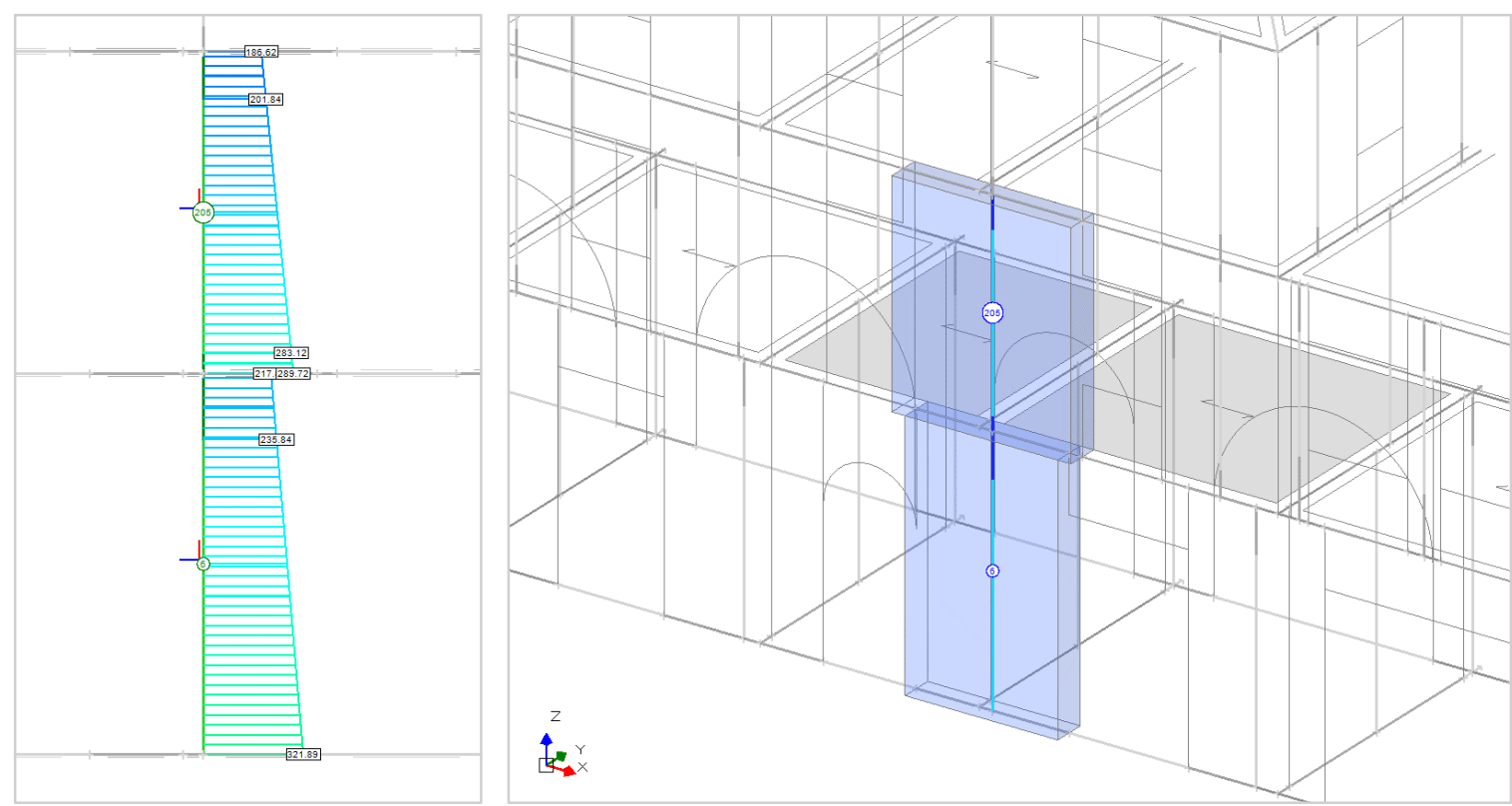

Figure 9. Axial force diagrams. Piers 6 and 205

This issue is caused by stress migration towards other elements. The amount of the decrease in axial force is at least equal to

$$
N_{205}-N_{6}=289.72-217.84=71.88 k N
$$

Considering that the total weight of Pier 205 is equal to $103 \mathrm{kN}$, the error is rather large. In fact, about $70 \%$ of the weight of Pier 205 is not transferred to pier 6 but migrates to other elements.

Another important aspect is the stress state in the spandrels. Despite they were modelled with the arch-behaviour, the spandrels are subject to shear and bending moments under the action of the sole vertical loads. The following table shows the characteristics of the stress state resulting in Spandrel 14.

\begin{tabular}{cccl}
\hline & Joint $\mathrm{i}$ & Joint $\mathrm{j}$ & \\
\hline $\mathrm{N}$ & 7.47 & 7.47 & $\mathrm{kN}$ \\
$\mathrm{V}_{\mathrm{y}}$ & 0.78 & 0.78 & $\mathrm{kN}$ \\
$\mathrm{V}_{\mathrm{z}}$ & -8.92 & 8.92 & $\mathrm{kN}$ \\
$\mathrm{M}_{\mathrm{x}}$ & -0.08 & -0.08 & $\mathrm{kNm}$ \\
$\mathrm{M}_{\mathrm{y}}$ & 3.41 & -10.85 & $\mathrm{kNm}$ \\
$\mathrm{M}_{\mathrm{z}}$ & 0.65 & -0.59 & $\mathrm{kNm}$ \\
\hline
\end{tabular}

Table 2. Stress state in Spandrel 14

As highlighted before, these issues are caused by the way the equivalent frame method is applied and construction phases analysis is able to overcome them. The results of the analysis performed with the proposed approaches are given in the following paragraphs. 


\subsection{Construction Phases Analysis}

The building is now analyzed with the construction phases approach described in $\S 2$. The following figures show the results of static linear analysis in terms of axial force diagram. Let us focus on the frontal alignment.

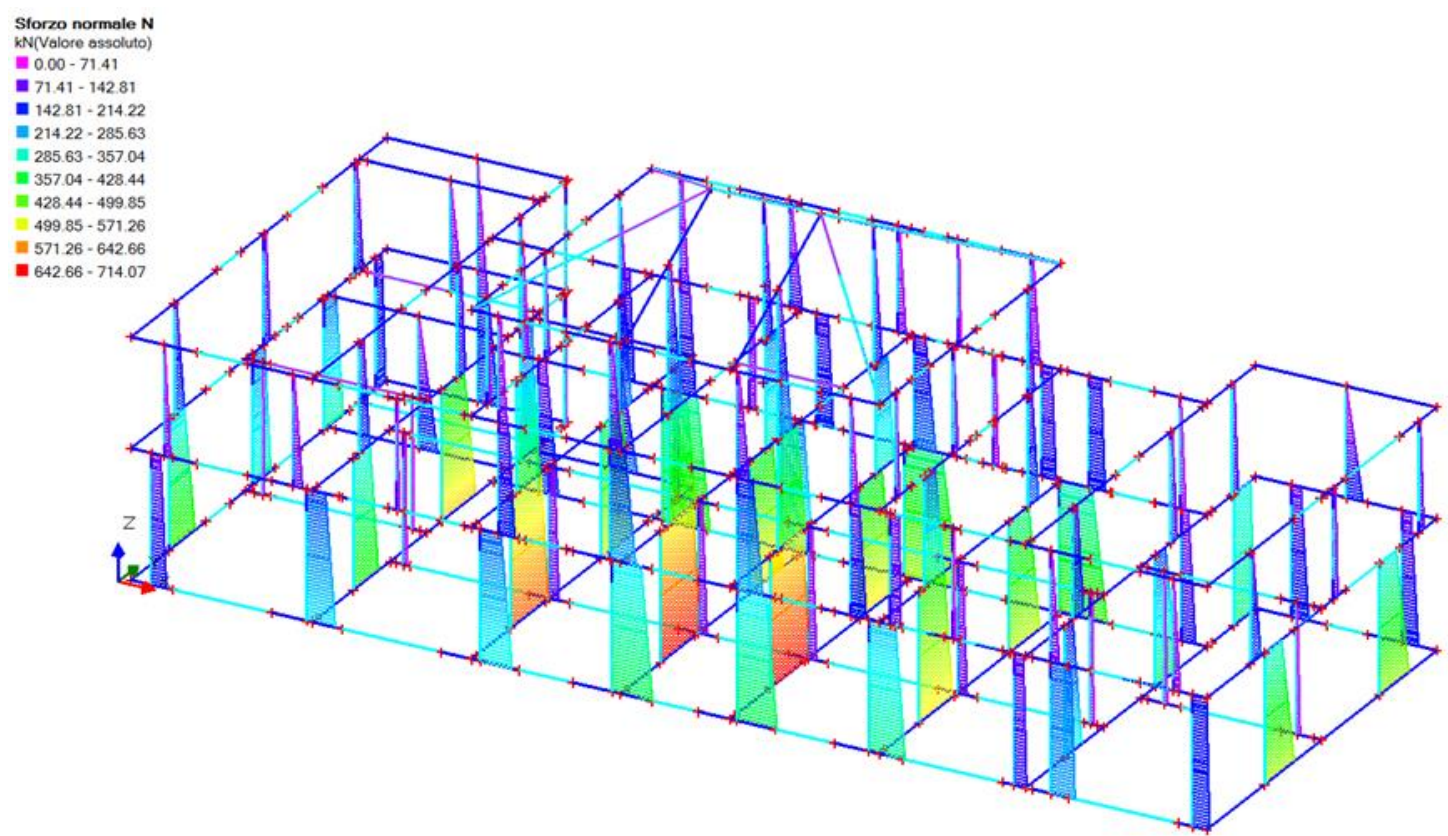

Figure 10. Static analysis results. Axial force diagrams

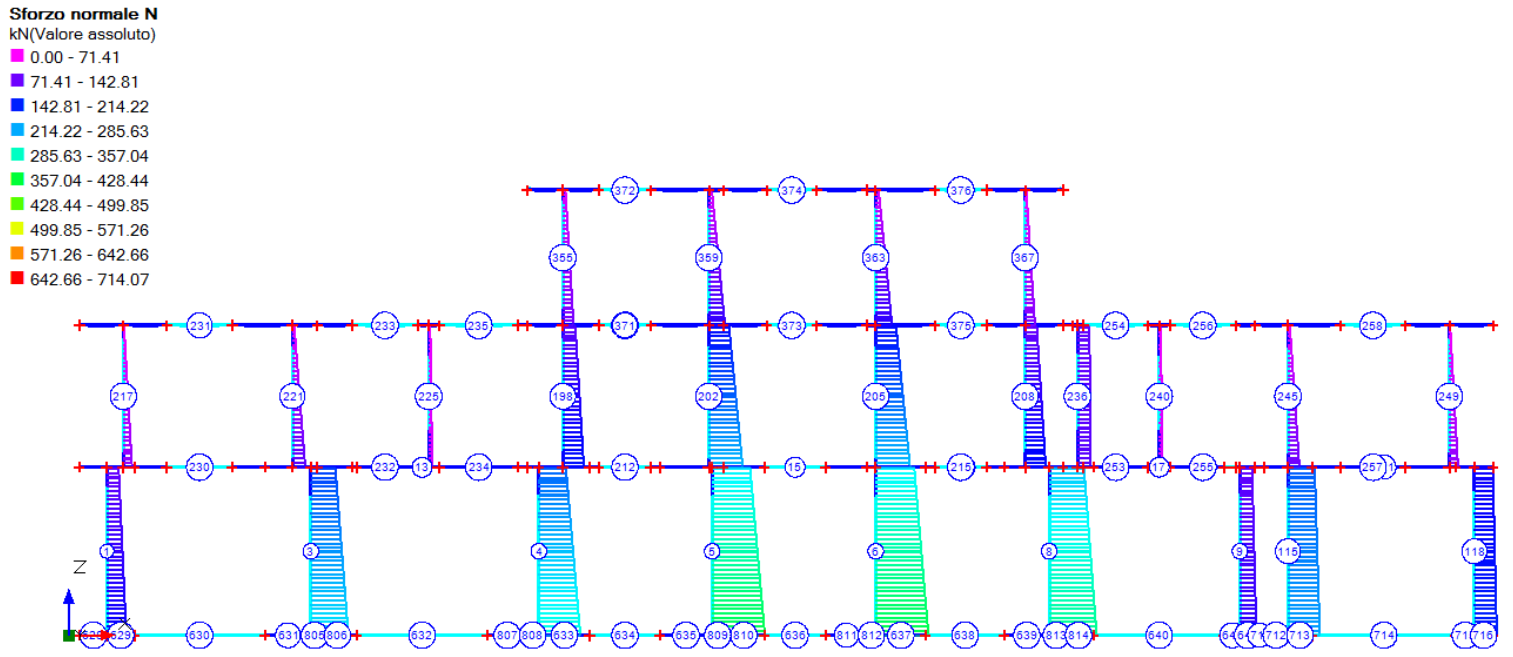

Figure 11. Axial force diagrams. Frontal alignment

The results of the analysis show no elements in tension. Comparing Figure 8 with Figure 11, we can notice in the latter a more rational stress distribution: there are no unnatural variation of axial force in continuous elements. Moreover, in-plane and out-of-plane bending moments are considerably reduced since now they are caused by the sole variable loads acting in Phase 1 . 


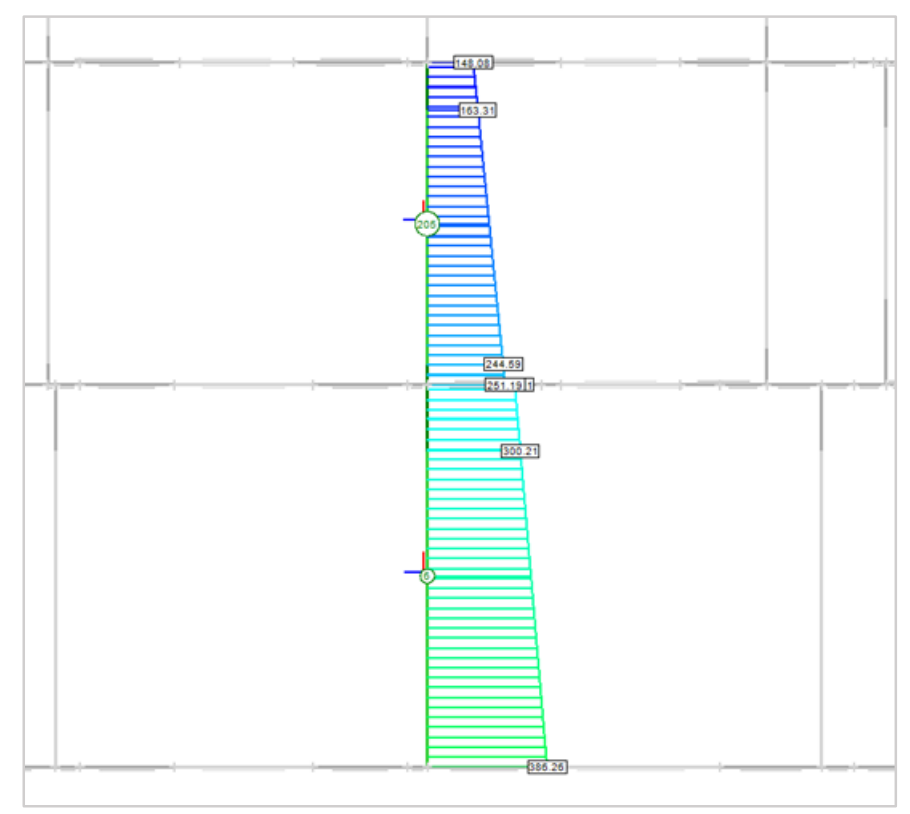

Figure 12. Axial force diagrams. Piers 6 and 205

Looking at Piers 6 and 205, we still notice a step in the axial force diagram, but this time it is the natural increment due to the weight of the spandrels:

$$
N_{6}-N_{205}=282.21-251.19=31.02 k N
$$

The following table show the characteristics of the stress state in Spandrel 14. We notice a significant reduction of the stress, consistent with the hypothesis of arch-behaviour.

\begin{tabular}{cccl}
\hline & Joint $\mathrm{i}$ & Joint $\mathrm{j}$ & \\
$\mathrm{N}$ & 0.00 & 0.00 & $\mathrm{kN}$ \\
$\mathrm{V}_{\mathrm{y}}$ & -0.05 & -0.05 & $\mathrm{kN}$ \\
$\mathrm{V}_{\mathrm{z}}$ & 0.00 & 0.00 & $\mathrm{kN}$ \\
$\mathrm{M}_{\mathrm{x}}$ & 0.00 & 0.00 & $\mathrm{kNm}$ \\
$\mathrm{M}_{\mathrm{y}}$ & 0.00 & 0.00 & $\mathrm{kNm}$ \\
$\mathrm{M}_{\mathrm{z}}$ & -0.04 & 0.04 & $\mathrm{kNm}$ \\
\hline
\end{tabular}

Table 3. Stress state in Spandrel 14

\subsection{Analysis of the construction stages}

The third approach refers to the analysis of the construction stages described in $\S 3$. As shown in Figure 6, part of the structure was built in 1918, while the rest was constructed in 1967 as part of the renovation interventions.

This approach is based on the hypotheses of the construction phases analysis, thus the results are similar to those obtained with the previous approach given in $\$ 4.2$. The only difference is the influence that the structure built in a later stage exerts on the original structure. This aspect is properly addressed only in the current approach, where the analysis under the action of the permanent loads is carried out by means of two models (0-A and $0-\mathrm{B})$.

Similarly to the previous approaches, we discuss the results of static linear analysis with a load combination that includes the sole vertical loads, focusing on the frontal alignment of the building (Figure 13, 14). The axial force distribution is regular, without piers in tension or particular stress migration. 


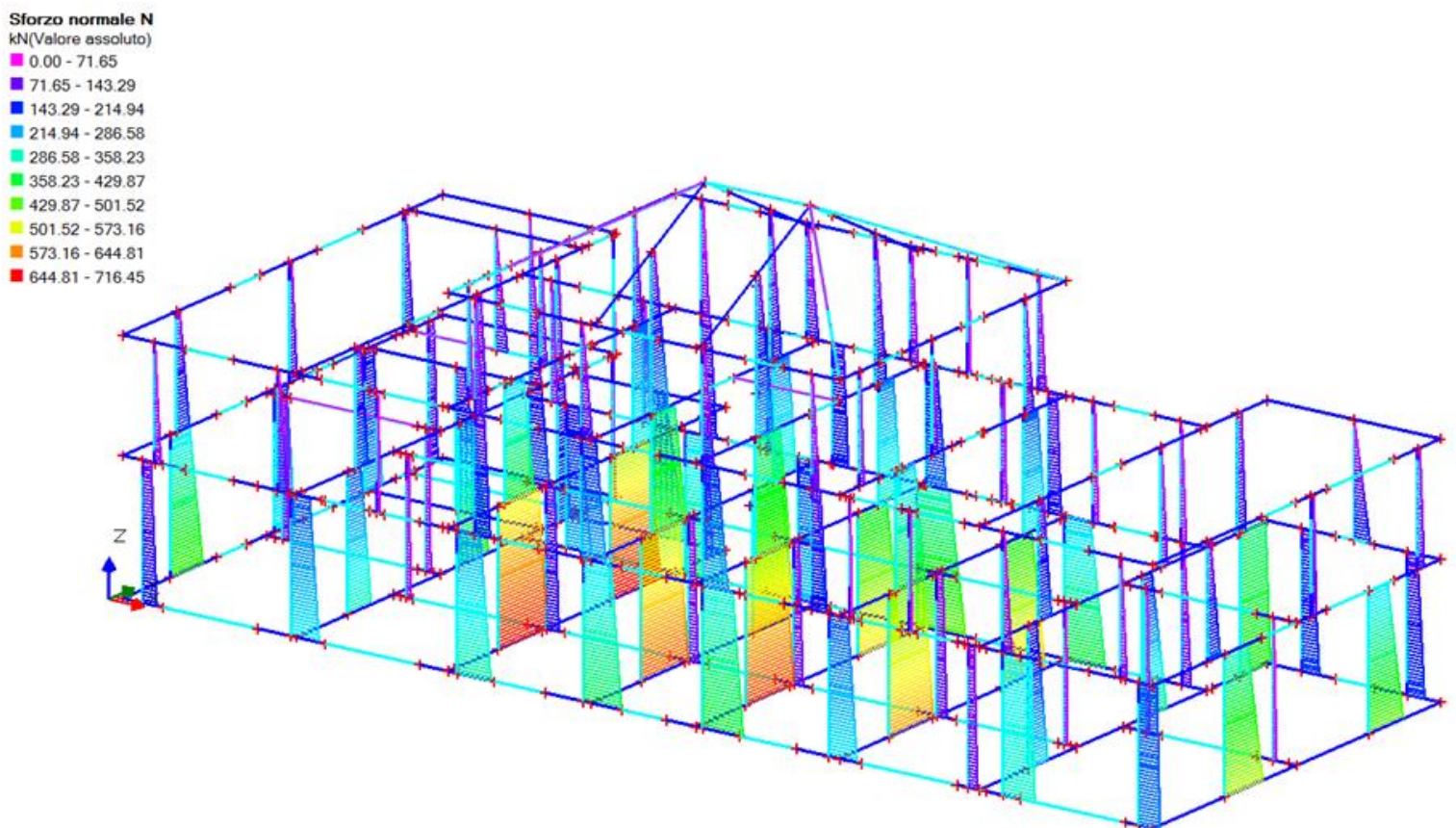

Figure 13. Static analysis results. Axial force diagrams

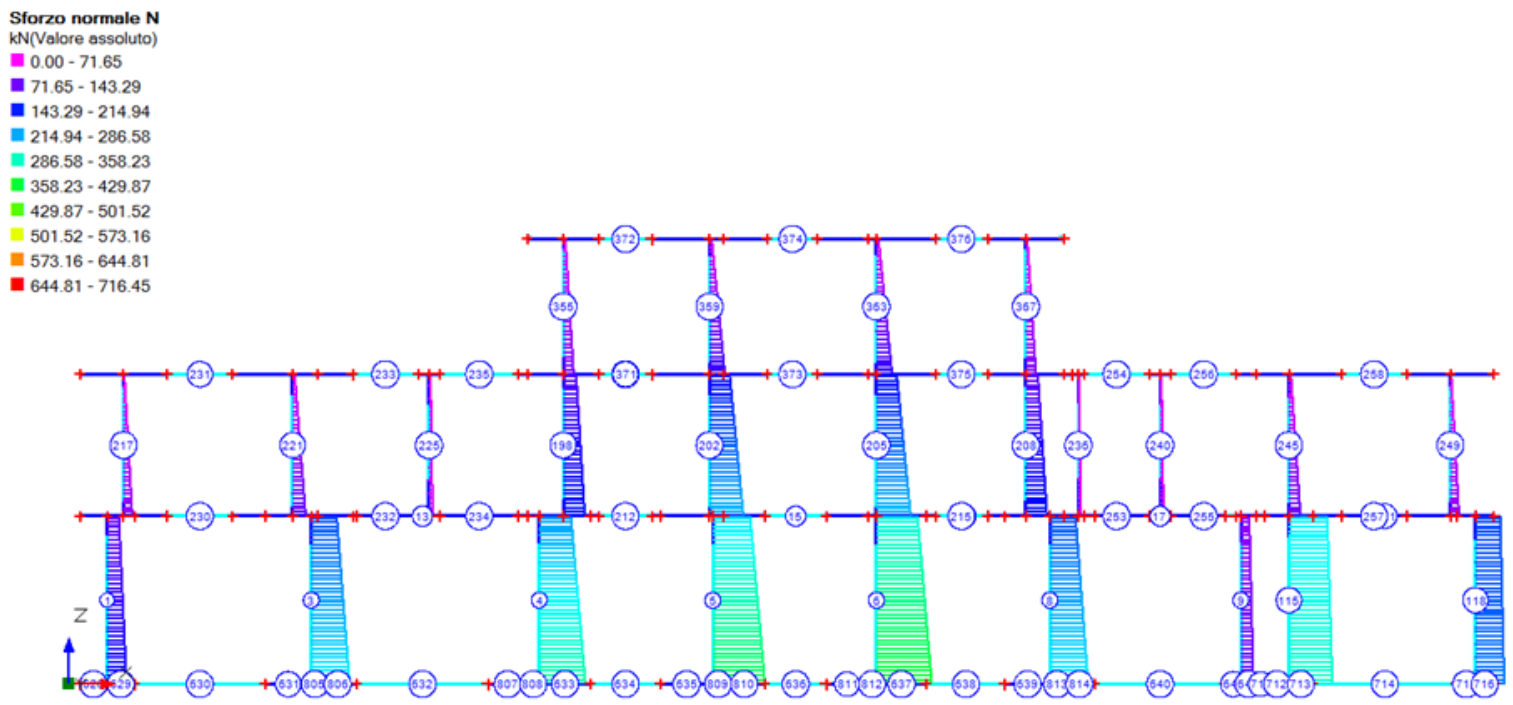

Figure 14. Axial force diagrams. Frontal alignment

As expected, the results are very similar to those obtained with the construction phases approach, although they are obtained through different models. This confirms the feasibility and the accuracy of the proposed methodology. 


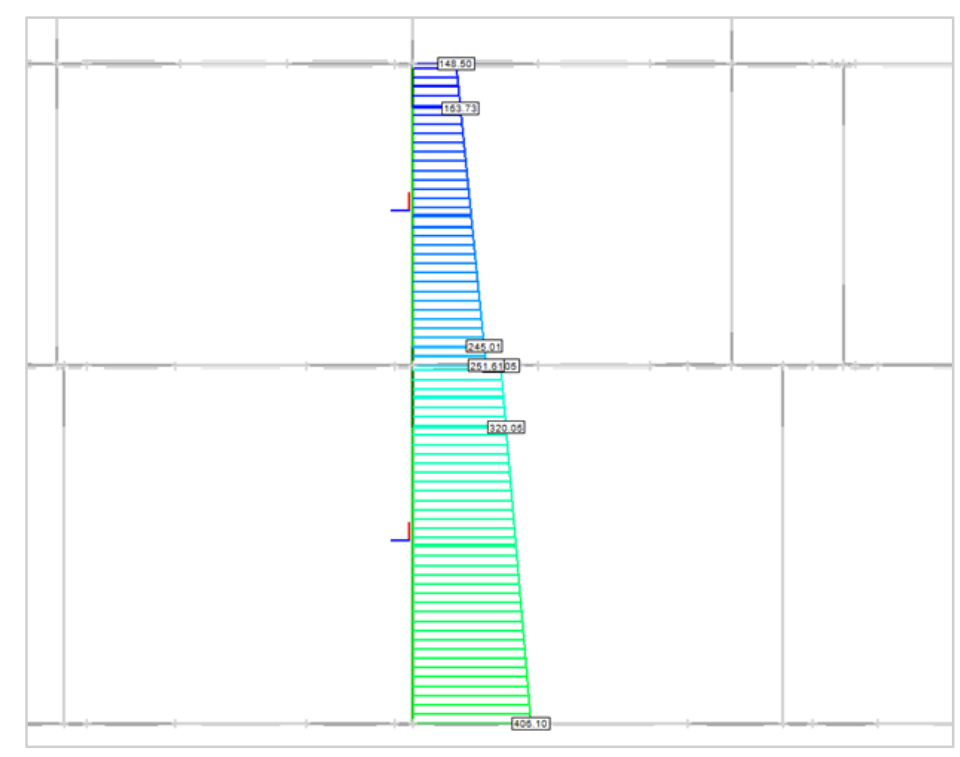

Figure 15. Axial force diagrams. Piers 6 and 205

Focusing on Piers 6 and 205 in Figure 15, we notice a larger value of the axial force with respect to the previous approach (Figure 12). The difference is more evident in Pier 6 at the ground floor, which is affected by the weight of the most recent part of structure. In this case the variation of axial force at the interface of the two piers is:

$$
N_{6}-N_{205}=302.05-251.61=50.44 k N
$$

Shear forces and bending moments in masonry piers are considerably reduced with respect to the standard approach, except for the original elements, which are also influenced by the permanent loads acting on the structure built in a later stage.

Again, the following table reports the stress state in Spandrel 14.

\begin{tabular}{cccl}
\hline & Joint $\mathrm{i}$ & Joint $\mathrm{j}$ & \\
\hline $\mathrm{N}$ & 0.00 & 0.00 & $\mathrm{kN}$ \\
$\mathrm{V}_{\mathrm{y}}$ & 0.27 & 0.27 & $\mathrm{kN}$ \\
$\mathrm{V}_{\mathrm{z}}$ & 0.00 & 0.00 & $\mathrm{kN}$ \\
$\mathrm{M}_{\mathrm{x}}$ & 0.00 & 0.00 & $\mathrm{kNm}$ \\
$\mathrm{M}_{\mathrm{y}}$ & 0.00 & 0.00 & $\mathrm{kNm}$ \\
$\mathrm{M}_{\mathrm{z}}$ & 0.22 & -0.20 & $\mathrm{kNm}$ \\
\hline
\end{tabular}

Table 4. Stress state in Spandrel 14

The stress is slightly larger than the previous approach since the spandrel belongs to the original structure and is affected by the most recent part of the building. Nevertheless, the stress state remains acceptable and consistent with the physical problem and the hypothesis of the proposed approach.

\subsection{Manual Calculation}

In order to verify the accuracy of the results let us perform a manual calculation of the axial force diagram. The model considered here includes Piers 6 and 205 as well as the pier above them and all the adjacent spandrels. The piers are considered as cantilever, while the spandrels are considered hinged at the two ends in their plane with arch-behavior. Therefore, under the action of vertical loads, the spandrel are unstressed and the piers are simply in compression. 
As shown in Figure 16, each pier is subjected to the self-weight and to additional forces, which account for the vertical loads acting on the spandrels and the slab loads at roof level. The values of these forces are:

$$
\begin{aligned}
& N_{3}=20.00 k N \\
& N_{2}=24.16 k N \\
& N_{1}=25.10 k N
\end{aligned}
$$

The following Table provides the dimension of each pier together with the specific weight and allows the calculation of the self-weight.

\begin{tabular}{lrrrl}
\hline & $\begin{array}{r}\text { Pier 363 } \\
\text { Second floor }\end{array}$ & $\begin{array}{r}\text { Pier 205 } \\
\text { First floor }\end{array}$ & $\begin{array}{r}\text { Pier 6 } \\
\text { Ground floor }\end{array}$ & \\
\hline Thickness & 0.50 & 0.50 & 0.50 & $\mathrm{~m}$ \\
Width & 2.70 & 2.70 & 2.30 & $\mathrm{~m}$ \\
Height & 3.10 & 3.25 & 3.85 & $\mathrm{~m}$ \\
Specific weight & 23.50 & 23.50 & 23.50 & $\mathrm{kN} / \mathrm{m}^{3}$ \\
\hline Self-weight & 98.35 & 103.10 & 104.05 & $\mathrm{kN}$ \\
\hline
\end{tabular}

Table 5. Calculation of self-weight

Given these data, the axial force acting on each pier can be calculated and the results may be represented in a diagram. The following Figure is a comparison of the axial force diagram obtained through analysis of the construction stages and the one calculated manually. We notice that the maximum deviation between the two diagrams, at the base of the wall, is equal to $11.49 \mathrm{kN}$, about $3 \%$ of the axial force in the corresponding section. Therefore, the analysis of the construction stages is very accurate especially if compared with the results of the standard approach, which show a much larger discrepancy with the manual calculation.
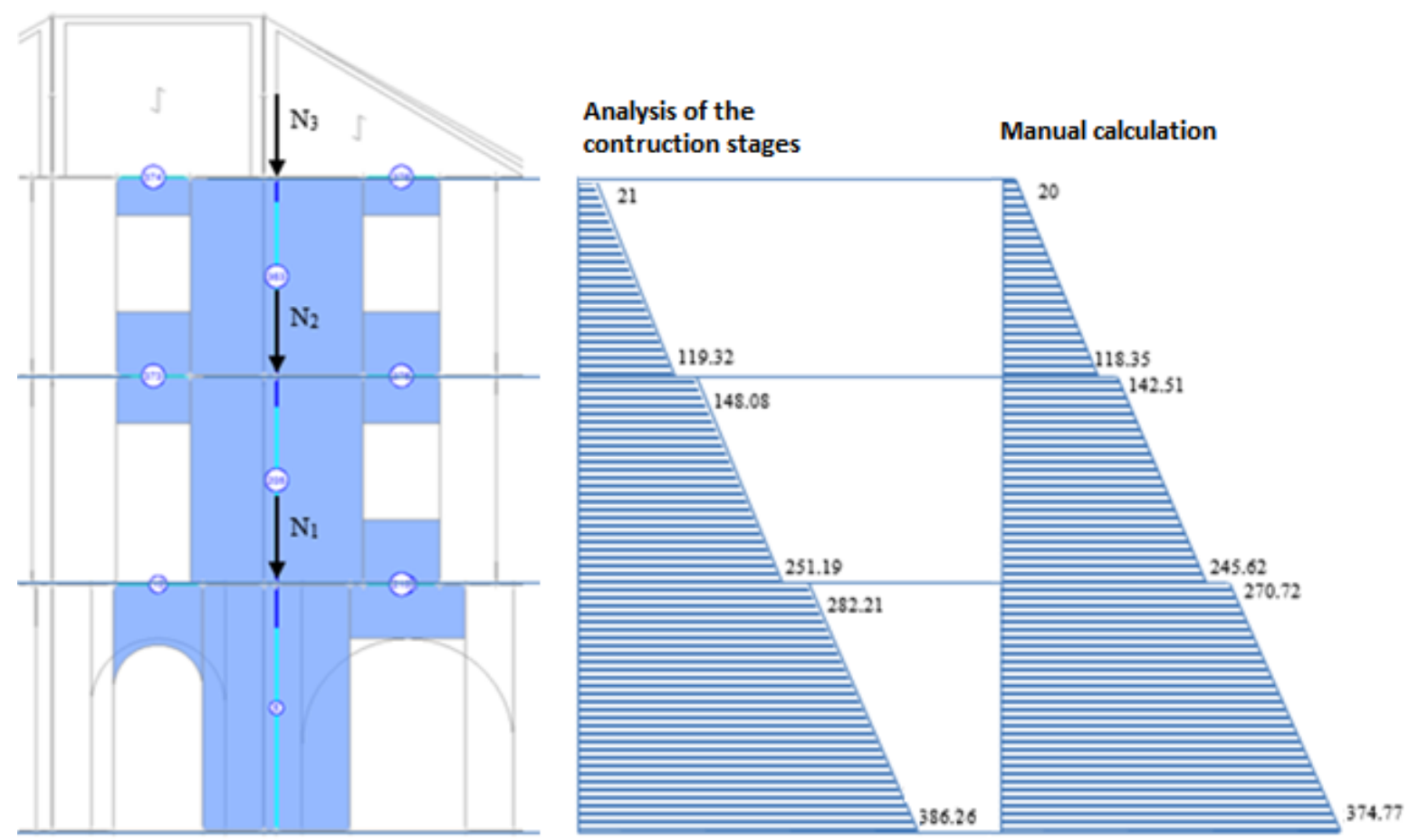

Figure 16. Comparison of axial force diagrams from analysis of the construction stages and manual calculation 


\section{CONCLUSION}

In this paper, a methodology aimed to improve the application of the equivalent frame model, through a more realistic stress distribution, was introduced. The approach, based on the construction phases analysis, consists in the use of different structural models for the analysis of the different load actions. The models vary in terms of mechanical characteristics of the materials, internal releases of the frames, joint restraints and load distribution. This allows to obtain a more accurate stress state of the elements and to overcome the typical issues related to the equivalent frame method when applied according to the standard approach.

Three phases have been defined. Phase 0 , where the sole permanent loads are applied, aims to catch the ability of the structure to settle under its own weight during the construction. Therefore, in this phase the equivalent frame is not completely established and the stress is distributed consistently with the influence areas of each element. Moreover, the spandrels are modelled with arch-behavior and remain unstressed under the action of vertical loads.

In Phase 1, only vertical variable loads are applied to the equivalent frame model. Besides axial force, piers may now be subjected to shear force and bending moments, while the spandrels still behave as arches.

In the third and last phase, Phase 2, horizontal variable loads (wind, seismic action) are applied. The hypothesis are the one of the standard equivalent frame model with no modifications.

Once the analyses are performed for each load action through the corresponding phase and model, the results are combined according to the relevant load combinations.

Furthermore, a procedure for the analysis of structures built in two different periods has been described. The analysis of the construction stages is based on the construction phases analysis but this time the original part of the structure and the one built in a later construction stage are treated differently. The application of the construction phases analysis in this case requires to split Phase 0 into two more Phases ( $0-\mathrm{A}$ and $0-\mathrm{B})$. This allow to properly assess the influence of the most recent structure on the original one.

The case study of a building rather regular in plan and in elevation was presented. The structure, built in two different periods, was analyzed according to three approaches: standard approach, construction phases analysis and analysis of the construction stages. The typical issues related to the standard application of the equivalent frame model were highlighted; especially with respect to the stress distribution, which in many case is affected by unrealistic stress migration. A comparison of the results obtained with the proposed approaches confirmed that they are more realistic and consistent with the real physical problem. The accuracy of the results has been proven through comparison with the stress state obtained through a simple manual calculation.

The building was analyzed though static linear analysis since the proposed methodologies mainly influence the structural behavior under the action of vertical loads. In a later work, the results of seismic analyses performed through the construction phases approach will be presented. The advantages of the proposed methodologies are evident in pushover analysis where the capacity curve of the structure is more realistic than the one obtained with the standard approach.

Finally, the proposed procedures represent an improvement of the equivalent frame method, leading to more accurate results with a slightly higher computational effort. This is particularly important, considering that the equivalent frame method is widely used in the engineering practice. However, the concepts of construction phases analysis could be applied even to more refined finite element models, since they are based on the differentiation of the structural model depending on the nature of the load actions. 


\section{REFERENCES}

[1] Ministero delle Infrastrutture e dei Trasporti. Decreto 14 gennaio 2008. Approvazione delle nuove norme tecniche per le costruzioni, §8.7.1. Gazzetta Ufficiale della Repubblica Italiana n. 29 del 4 febbraio 2008, Supplemento ordinario n.29. (in Italian)

[2] Ministero delle Infrastrutture e dei Trasporti. Circolare. n. 617 del 02 febbraio 2009. Istruzioni per l'applicazione delle Nuove Norme Tecniche per le costruzioni, §C8A.4. Gazzetta Ufficiale della Repubblica Italiana n. 47 del 26 febbraio 2009, Supplemento ordinario n.27. (in Italian)

[3] Eurocode 6: Design of masonry structures - Part 1-1: General rules for reinforced and unreinforced masonry structures, EN 1996-1-1, 2005.

[4] Eurocode 8: Design of structures for earthquake resistance - Part 1: General rules, seismic action and rules for buildings, EN 1998-1, 2005.

[5] AA.VV, Manuale delle Murature Storiche: Analisi e conoscenza del costruito storico in muratura, Direttore Scientifico A. Borri, a cura di C. Donà. DEI Tipografia del Genio Civile, Roma, 2011. Appendice $§$ A.2.7. (in Italian)

[6] M. Ludovico, R. Fico, E.A. Cordasco, A. Prota, G.M. Verderame, G. Manfredi, Alcune considerazioni sull'utilizzo del software tecnico nella Ricostruzione dell'Abruzzo, a cura dell'Università di Napoli Federico II e del Consorzio RELUIS. (in Italian)

[7] B. Calderoni, E.A. Cardasco, P. Lenza, G. Pacella, Structural behaviour of masonry spandrels: experimental evaluation and reinforcing, Proceedings of Prohitec Conference, Rome, June 2009, Taylor \& Francis Group, London, pag. 1591-1596.

[8] B. Calderoni, E.A. Cardasco, P. Lenza, G. Pacella, Analisi numerica su base sperimentale del comportamento strutturale delle fasce murarie di piano, Atti del XIII Convegno Nazionale ANIDIS "L'Ingegneria Sismica in Italia”, Bologna, June-July 2009, ed. PATRON. (in Italian)

[9] Aedes Software, Aedes.PCM: Progettazione di Costruzioni in Muratura, Version 2015, www.aedes.it 